\title{
Retaining walls with relief shelves
}

\author{
Hany F. Shehata ${ }^{1,2,3}$
}

Received: 17 June 2015/Accepted: 15 February 2016/Published online: 30 March 2016

(C) Springer International Publishing Switzerland 2016. This article is published with open access at Springerlink.com

\begin{abstract}
Cantilever retaining wall with pressure relief shelves is considered as a special type of retaining wall. The concept of providing pressure relief shelves on the backfill side of a retaining wall reduces the total earth pressure on the wall, which results in a reduced thickness of the wall and ultimately in an economic design of a cantilever wall. A limited number of solutions and measurements can be found for this type of wall in the literature. The shapes of the measured earth pressure distributions differ among studies because the model scales were different; for example, the wall during one measurement was permitted to move but was not permitted to move in the other measurements. This paper presents a Finite Element analysis of this type of wall using PLAXIS2D-AE.01. The reduced total active earth pressure due to the provisioning of shelves is depicted. It was found that the shelves had a significant effect on the resulting earth pressure distribution. The distribution approximately followed the distribution of the solution by Klein (Calculation of retaining walls (in Russian). Vysshaya Shkola, Moscow, 2014). It also followed the shape of the measurements of Yakovlev (Experimental investigation of earth pressure on walls with two platforms in the case of breaking loads relieving on the backfill. Odessa Institute of Naval Engineers, pp 7-9, 1974). A parametric study was conducted to enable a discussion of the effects of the number of shelves, shelf rigidity, and shelf position on the resulting
\end{abstract}

Hany F. Shehata

hanyfarouk808@gmail.com

Soil-Structure Interaction Group (SSIGE), Cairo, Egypt

2 EHE-Consulting Group, Cairo, Egypt

3 EHE-Consulting Group, Ajman, United Arab Emirates (UAE) distribution of the lateral earth pressure, wall top movement, and acting maximum flexural moment of the wall. For high retaining walls and for some repair systems for constructed walls that have problems with stability, it is recommended to provide the cantilever wall with a shelf at a third of the wall height from the top of the wall or more shelves at different levels. Suggested updates are provided to enhance the manual solution of Klein in the calculation of the acting maximum bending moment of the wall.

Keywords Special retaining structures - Relief shelves · Earth pressure $\cdot$ Repair $\cdot$ Maximum moment $\cdot$ High retaining walls

\section{Introduction}

Retaining walls are constructed to sustain the lateral pressure of the earth behind them. Earth-retaining structures include cantilever retaining walls, sheet pilings, bulkheads, basement walls, and special types of retaining walls. The special types of walls include counterfort retaining walls, buttress retaining walls, and retaining walls that rest on piles. Retaining walls with relief shelves can also be considered as a special type of retaining walls. Some reports by engineers have stated that using reinforced soil walls is the most economical method for constructing high walls without studying walls with shelves in their reports. High cantilever retaining walls may also be the most economical solution, according to the study case, when relief shelves are added on the backfill side of the wall. Such walls are called Retaining Walls with relief shelves. The relief shelves have the advantages of decreasing the acting lateral earth pressure and increasing the overall stability of the retaining wall. If there is a construction near the wall and if 
the soil reinforcement cannot be applied, the use of this type of wall can be the most effective tool toward cost reduction and overall safety improvement. The use of recently developed soil reinforcement methods, which needs a free long distance behind the wall for the construction purpose, is widely preferred and accepted by engineers in Egypt and overseas, but what is the solution if there are some problems or obstructions to constructing these wall types? Adding shelves to a cantilever retaining wall may be a solution toward achieving stability and cost control. The study of this type of retaining wall is a somewhat un-noticed area in the study of retaining structures. Few studies have been carried out on the real behavior of this type of wall. Therefore, studying the effectiveness of this type of retaining wall is required for its use in practical application. Case studies are also required to present the most economical solution to the practice in various cases.

\section{Brief literature review}

The classification of this type of wall started to be studied in 1927 at the University of Western Australia during an applied Geo-mechanics lecture. The lecture presented the classification of flexible retaining walls, and the wall with shelves was classified as a flexible retaining wall. Many years later, Jumikis [9] studied the effect of adding one or more relief shelves to a counterfort wall to increase the stability of the wall. He extended the relief shelves up to the theoretical rupture surface. Jumikis [9] found that the relief shelves decrease the lateral earth pressure on the wall and increase the stability of the overall retaining structure. Jumikis [9] illustrated theoretically the method of stability analysis of a counterfort wall with two relief shelves, as shown in Fig. 1.

Raychaudhuri [12] found the magnitude of the reduction in the total active earth pressure and its distribution due to the provisioning of a relief shelf in a retaining wall. He presented the reduction factors in charts for various locations and widths of relief shelves. Raychaudhuri [12] suggested that Coulomb's (1776) theory for earth pressure would be applicable to this type of wall and subsequently finished his charts. Raychaudhuri [12] performed experimental studies to verity the stability of the wall, but he could not determine the earth pressure behind the wall due to the simple model that he used. In a discussion paper [2] on Raychaudhuri's work, Murthy did not agree with the concept of retaining walls with shelves due to the construction complexity [3]. In addition, Narain suggested in their paper that this type of wall requires a comprehensive study, while Sreenivasa Rao suggested in the same paper to pursue the work of Raychaudhuri using a more complex model [3].

Yakovlev [13-16, 17] experimentally studied in detail the effect of the relief shelves. From 1964 to 1966, Yakovlev performed several experiments with one relief shelf to investigate different factors, such as the distribution of pressure over the height of the wall as a function of the position and the dimensions of the platform under the effect of a variably distributed load on the backfill surface; the distribution of the pressure on the platform as a function of the intensity and the location of the load; the nature of the change in pressure on the wall and on the platform in the presence of forward movements of the wall; the size of the sliding wedge and the position of the sliding surface for walls with platforms; and the stress of the backfill behind the wall. In 1975, Yakovlev experimentally investigated
Fig. 1 Adapted from [9], concept of counterfort retaining wall with two relief shelves

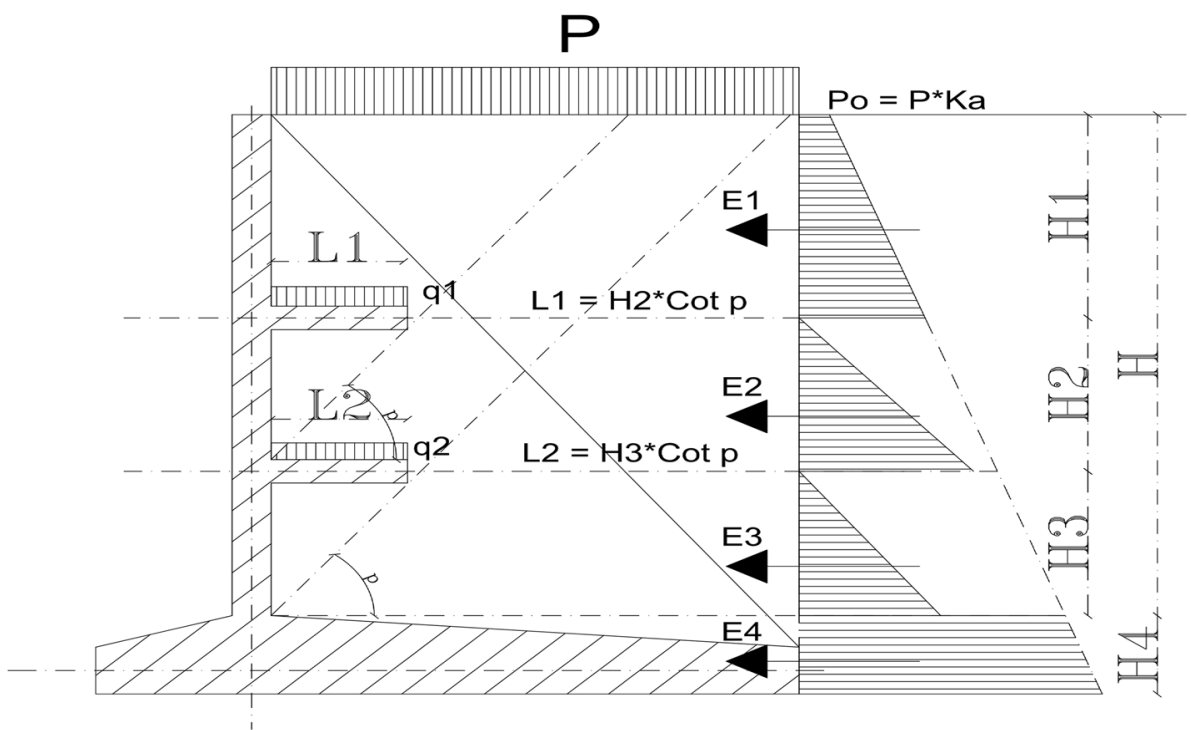


the earth pressure distribution on a wall with two relief shelves, as shown in Fig. 2 [3]. Yakovlev concluded that when the wall was permitted to move, an internal sliding surface developed from the end of the shelf. The surface formed in the backfill zone above the shelf. Yakovlev studied the position of the internal and external sliding surfaces and the width and embedded depth of the shelf. For the same embedded depths of a shelf, the dimensions of the sliding zone increase with increasing platform width.

Phatak and Patil [11] discussed a theoretical concept for computing the earth pressure due to the effect of relief shelves using Rankin's theory. Phatak and Patil [11] corrected an error in Raychaudhuri's [12] solution. Raychaudhuri [12] considered the effect of the relief shelf by deducting the weight of the soil above the relief shelf from the failure wedge; however, the change in the center of gravity for the failure wedge was not taken into consideration. Phatak and Patil [11] calculated the effect of the center of gravity shift and concluded that the introduction of the relief shelf reduces the active earth pressure thrust and the lever arm.

In his book, Bell [1] assumed that there is a transition zone under the shelf. After this transition zone, the earth returns to its original distribution; i.e., to the distribution of the cantilever retaining wall, as shown in Fig. 3a. Jang [8] assumed this transition to be a horizontal line, as shown in Fig. 3b. Fuchen and Shile [7] studied methods of calculating the earth pressure when adding a single relief shelf. Liu and Lin proposed an analytical method to calculate the

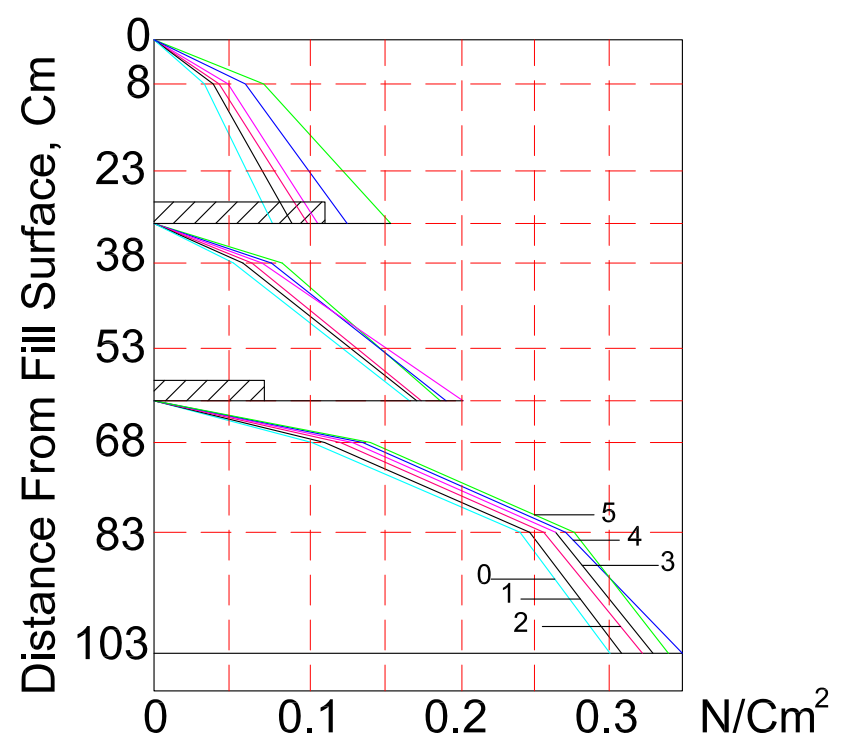

Fig. 2 Adapted from Yakovlev, 1975, distribution of earth pressure for a retaining wall with two relief shelves at five loading stages from 1 to 5 (a)

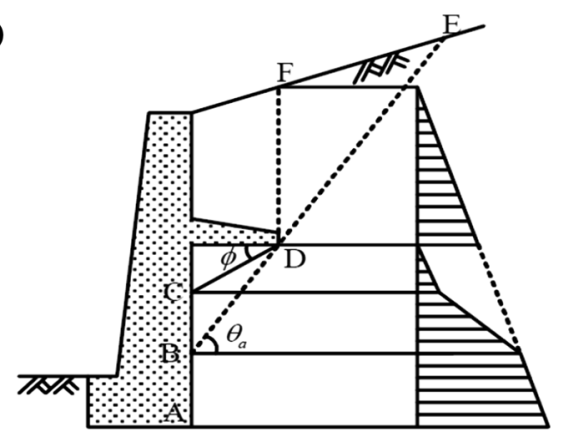

(b)

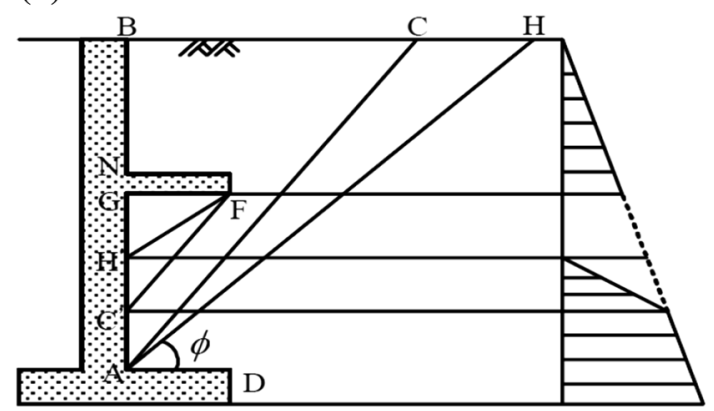

Fig. 3 Earth pressure distribution of retaining wall with relieving shelf. a Adapted from Bell [1]. b Adapted from Jang [8]

earth pressure for different shelf widths. Figure 4a shows their suggested distribution of the lateral pressure when the relief is extended to the rupture surface, while Fig. $4 \mathrm{~b}$ shows their suggested distribution when the shelf width is not extended. For the case of the shelf extension, they suggested that the distribution of the earth pressure starts at zero under the shelf and increases linearly with depth. For a short shelf, they proposed an additional rupture surface starting from the end of the shelf and running parallel to the global rupture line. At this depth, they assumed that the transition zone of the earth pressure is a horizontal line, as in the assumption of Jang [8].

Yoo et al. $[18,19]$ measured the earth pressure acting on a wall with one shelf that is extended to the theoretical rupture surface. They constructed their model and simulated the excavation stage with slope angles of $50^{\circ}$ and $90^{\circ}$, and subsequently, they installed the wall and inserted the compacted backfill. They also attempted to verify the results from the finite element method (FEM) using the Mohr-Coulomb model. Figure 5 shows the comparison between the results of the measurements, FEM, Fuchen and Shile [7], and Bell [1]. It can be observed that the FEM calculated lateral earth pressures under the shelf that were greater than those calculated using the other methods. They concluded that the FEM has limitations and that the other methods are in good agreement with each other. 
(a)

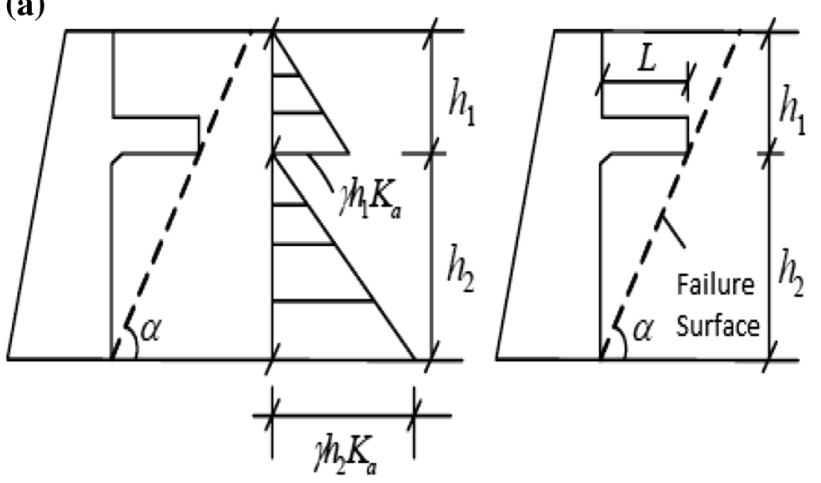

(b)

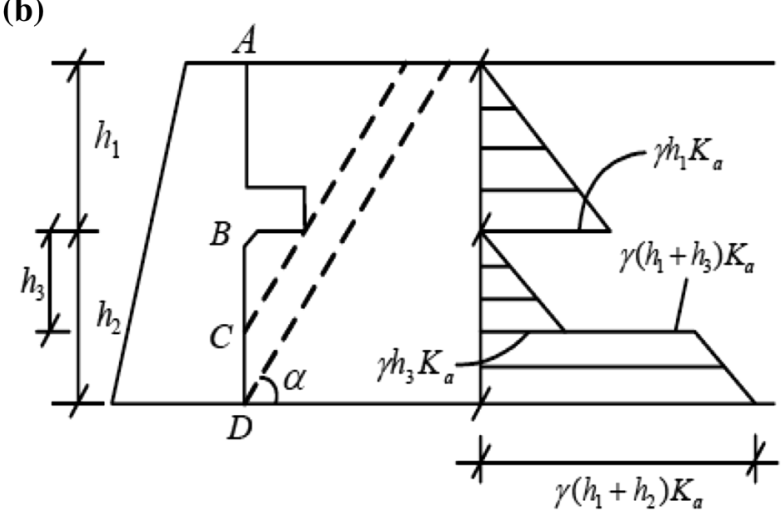

Fig. 4 Calculation of active earth pressure adapted from Fuchen and Shile [7]. a Long relief shelf. b Short relief shelf

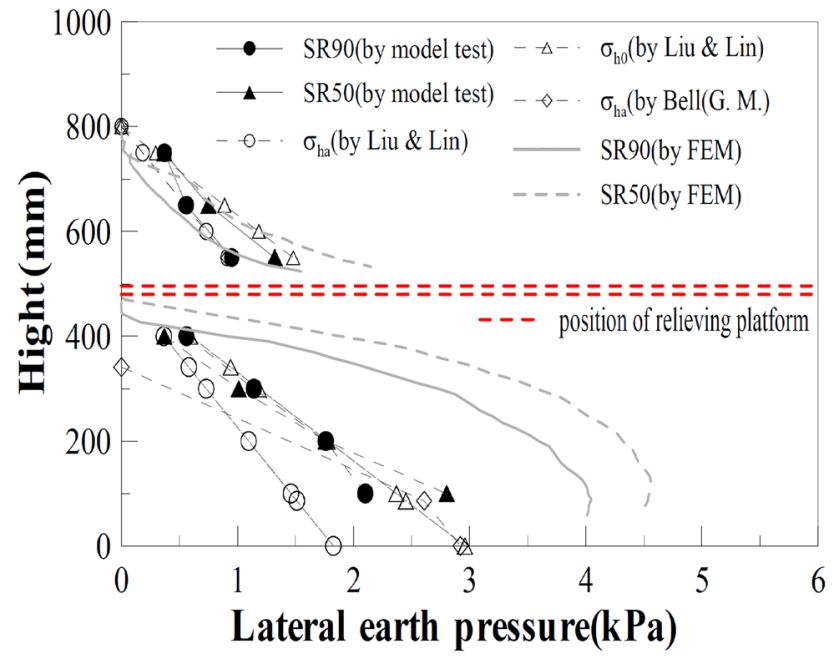

Fig. 5 Comparison of lateral earth pressures for a retaining wall with relieving shelf adapted from Yoo et al. [18]

Here, I include some comments: the practical model that they utilized and the other analytical methods consider that the base of the wall does not move and is not rotated, which is not realistic. For their solution from the FEM, they installed the wall on a defined thickness of soil media. This

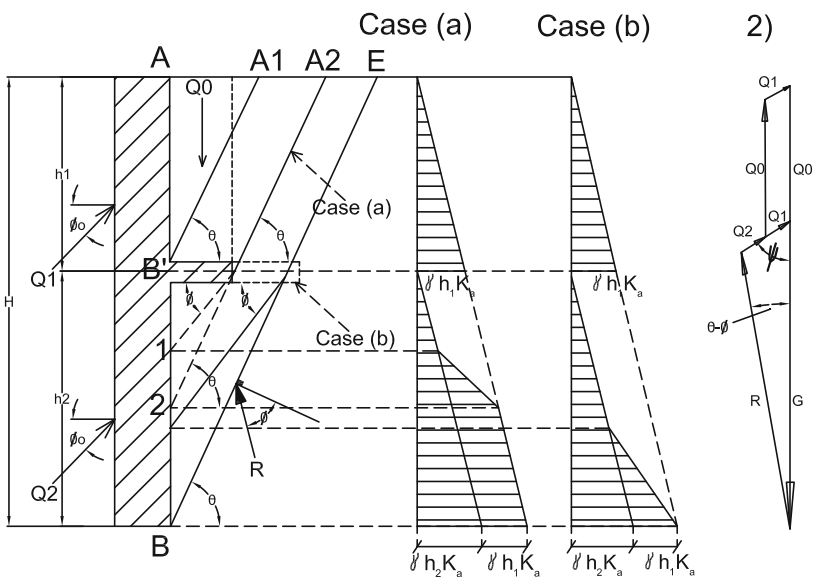

Fig. 6 Solution of Klein [10], adapted from Klein [10]. a Short shelf. b Long shelf

thickness had settled and permitted the footing to rotate, even if by a small amount. These results should increase the lateral pressures, as shown in their FEM; however, the use of the Mohr-Coulomb soil model results in a slight increase in the lateral pressure due to the unloadingreloading conditions as they modelled the construction stages starting from the excavation stage to the backfilling stage.

In his reference, Klein [10] discussed a distribution for the earth pressure above and under the shelf that is shown in Fig. 6. His distribution is approximately compatible with the measurements of (Yakovlev 1975). His solution defined a sloped transition line using two defined points. The distribution may also be compatible with the Finite Element solution using more advanced soil models, which will be studied here. It can be observed that there are two distributions: (a) for the shelf that is not extended to the rupture line and (b) for the shelf that is extended to the rupture line.

\section{Research objectives}

The comparison in Yoo et al. [18] demonstrates that the lateral earth pressure is high under the shelf, which may result in no decrease or a slight decrease in the acting maximum bending moment of the wall. This results in a small decrease in the reinforcements and in the concrete quantities. This conclusion may abolish the purpose that this type of wall was established for. The literature review presented significant differences in the calculation methods and measurements. Therefore, dedicated studies are needed by engineers to study the effectiveness of using this type of retaining structure. In this paper, we have three objectives. The first is to compare the distributions of the lateral earth pressures for cantilever retaining walls with and without relief shelves. This is achieved by applying the FEM 
solution from PLAXIS2D-AE.01 using the Hardening soil model. This comparison should clarify the effectiveness of providing shelves for the cantilever retaining walls. The second objective is to conduct a parametric study to qualify the effect of several factors, such as the number of shelves, shelf height, shelf width, and shelf thickness, on the earth pressure distribution and wall deformation. The final objective is to compare the maximum bending moment that is calculated using the FEM solution and the analytical solution of Klein [10]. Suggested updates and notes for the calculation of the maximum bending moment shall be provided for Klein's solution to enhance the results.

\section{Modeling}

To achieve the objectives of this study, thirty one (31) models are analyzed using PLAXIS 2D-AE.01. The models consist of a retaining wall with a height equal to $10.0 \mathrm{~m}$ and a footing width equal to $5.0 \mathrm{~m}$. The wall and footing thicknesses are 0.50 and $0.80 \mathrm{~m}$, respectively. The embedded width of the footing inside the backfill from the centerline of the wall is $3.0 \mathrm{~m}$. The retaining structure material is reinforced concrete, which is modeled using a linear elastic model with a Young's modulus (E) of $21,000 \mathrm{MPa}$, specific weight of $25 \mathrm{kN} / \mathrm{m}^{3}$, and Poisson's ratio (v) of 0.15 . The Hardening Soil Model was adopted to simulate the soils. The soil media before constructing the wall is dense sand. The parameters of the base soil are as follows: angle of the internal friction $(\varphi)$ is equal to $38^{\circ}$, dilatancy angle $(\Psi)$ is $8^{\circ}$, unit weight $(\gamma)$ is $18.0 \mathrm{kN} / \mathrm{m} 3$, the Oedometer modulus of elasticity $\left(\mathrm{E}_{\mathrm{oed}}\right)$ is the same as the modulus of elasticity at $50 \%$ of the ultimate stress $\left(\mathrm{E}_{50}\right)$ that equals $40.0 \mathrm{MPa}$; the unloading reloading elastic modulus $\left(\mathrm{E}_{\mathrm{ur}}\right)$ is equal to $120.0 \mathrm{MPa}$; and the power factor $(\mathrm{m})$ is equal to 0.50 . The backfill after the wall is constructed is compacted sand. The backfill parameters are as follows: $\varphi$ is equal to $32^{\circ}, \Psi$ is $2^{\circ}, \gamma$ is $17.0 \mathrm{kN} / \mathrm{m}^{3}$; $\mathrm{E}_{\text {oed }}$ is the same as $\mathrm{E}_{50}$ that equals $10.0 \mathrm{MPa}$; $\mathrm{E}_{\mathrm{ur}}$ is $30.0 \mathrm{MPa}$; and $\mathrm{m}$ is equal to 0.50 . The stated soils parameters are listed in Table 1. The angles of external friction $(\delta)$, which are defined to the interfaces, are listed in Table 1 . The study of the dilation effect is not considered, but the dilatancy angle is assumed equal to $(\varphi-30)$.

The wall is analyzed for the cases of cantilevers with a single relief shelf and with two relief shelves. The first shelf is located at a depth $h_{1}$ from the wall top, and the second shelf is located at a depth $\mathrm{h}_{2}$ from the wall bottom. The relief shelf has different widths of $1.0,2.0$, and $3.0 \mathrm{~m}$, according to the case being studied. The relief shelf also has different thicknesses of $0.1,0.2,0.3,0.4,0.5 \mathrm{~m}$, according to the case being study. Figure 7 shows the discretization of the models.

Three (3) models are constructed to clarify the effectiveness of adding one shelf and of adding two shelves to the cantilever retaining wall. Twenty one (21) models are constructed with constant shelf locations and different shelf widths (b) and thicknesses ( $t_{s}$ ) to qualify the effect of the shelf rigidity on the resulting earth pressure distribution, top movement of the wall, and maximum flexural moment that is acting on the wall. The last seven (7) models are constructed using one shelf with a certain width and thickness, but the shelf depth $\left(\mathrm{h}_{1}\right)$ is varied in the different models to qualify the effect of the shelf position. Finally, some models are theoretically analyzed using Klein's [10] solution, and the results for the maximum bending moments are compared to those found using the FEM solution. The different models are listed in Table 2.

\section{Analyses and discussions}

\section{Effect of providing shelves}

First, the effectiveness of the provided shelves should be discussed. The shelves, as stated in the literature, generate conflicting views by researchers. Some researchers are accepting of the concept of providing shelves to increase stability, while others reject this concept. Figure 8 shows the resulting distributions of the lateral earth pressures in the cases of a cantilever with one shelf and the case of one with two shelves.

It can be observed that providing relief shelves to the retaining structure significantly decreases the lateral earth pressure. For the single shelf at a depth $\mathrm{h}_{1}$ equal to $7.0 \mathrm{~m}$, the distribution is similar to the distribution for the cantilever at $7.0 \mathrm{~m}$ over the shelf, with a concentration of the pressure directly above the shelf. This increased "concentration" of the pressure is the result of the effect of the rigid shelf $(0.50 \mathrm{~m}$ thickness and $2.0 \mathrm{~m}$ width). The lateral pressure returns to its initial value from zero directly under the shelf and increases linearly with a slope that is less than the slope in the cantilever case. By providing two shelves, the lateral pressure directly above the shelves also exhibits
Table 1 Hardening soil model parameters for the base and backfill soils

\begin{tabular}{llllllll}
\hline Parameter & $\varphi^{\circ}$ & $\Psi^{\circ}$ & $\delta^{\circ}$ & $\gamma\left(\mathrm{kN} / \mathrm{m}^{3}\right)$ & $\mathrm{E}_{\text {oed }}=\mathrm{E}_{50}(\mathrm{MPa})$ & $\mathrm{E}_{\mathrm{ur}}(\mathrm{MPa})$ & $\mathrm{m}$ \\
\hline Base soil & 38 & 8 & 26 & 17.0 & 10.0 & 30.0 & 0.50 \\
Backfill & 32 & 2 & 22 & 18.0 & 40.0 & 120.0 & 0.50 \\
\hline
\end{tabular}




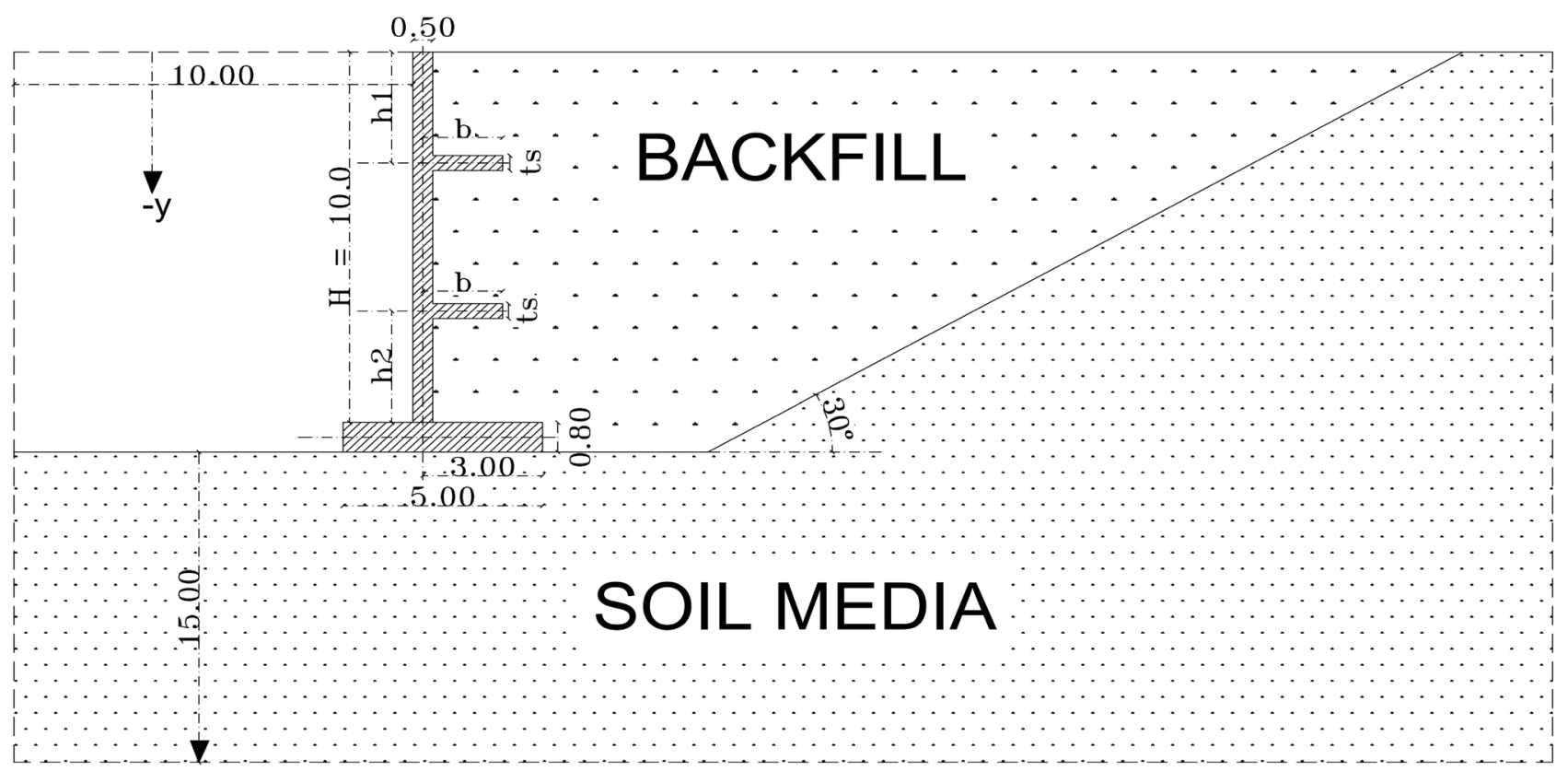

Fig. 7 Discretization of the research models

Table 2 Research model details

\begin{tabular}{|c|c|c|c|c|c|}
\hline Objectives & Number of models & $\mathrm{t}_{\mathrm{s}}(\mathrm{m})$ & $\mathrm{b}(\mathrm{m})$ & $\mathrm{h}_{1}(\mathrm{~m})$ & $\mathrm{h}_{2}(\mathrm{~m})$ \\
\hline \multirow[t]{3}{*}{ Effect of providing shelves } & 1 & - & - & - & - \\
\hline & 1 & 0.5 & 2.0 & 7.0 & - \\
\hline & 1 & 0.5 & 2.0 & 3.0 & 3.0 \\
\hline \multirow[t]{6}{*}{ Effect of shelf rigidity } & 4 & $0.1,0.2,0.4,0.5$ & 2.0 & 3.0 & - \\
\hline & 4 & $0.1,0.2,0.4,0.5$ & 2.0 & 7.0 & - \\
\hline & 4 & $0.1,0.2,0.4,0.5$ & 2.0 & 3.0 & 3.0 \\
\hline & 3 & 0.50 & $1.0,3.0,4.0$ & 3.0 & - \\
\hline & 3 & 0.50 & $1.0,3.0,4.0$ & 7.0 & - \\
\hline & 3 & 0.50 & $1.0,3.0,4.0$ & 3.0 & 3.0 \\
\hline Effect of shelf position & 7 & 0.30 & 2.0 & $1,2,3,4,5,6,7$ & - \\
\hline
\end{tabular}

an increase in the pressure for the same reason. It can be observed that the pressure in the zone between the two shelves starts at zero and returns to the path of the cantilever case. This conclusion is in agreement with the assumption of Klein's [10] solution.

The resulting overall safety factor for the cantilever is 1.25. By providing single and double shelves, the factor increases to 1.45 and 1.55 , respectively. This means that the shelves also increase the stability, especially when providing two shelves. The effect of providing shelves at a level near the wall top is smaller than the effect of that which results from using a shelf at the lower level, this is, the effect of extending the shelf to the rupture surface that is increasing the stability.

\section{Effect of shelf rigidity}

The shelf rigidity "stiffness" is affected by the shelf width and the thickness. The shelf width, as presented above, should be extended to the rupture surface to increase stability; however, it may not be extended if the stability is achieved without shelves. In this case, the shelves are provided to decrease the lateral pressure and the maximum moment acting on the wall. In addition, the shelf thickness is designed according to the applied flexural moment on the shelf, which depends on the shelf width. In the case of decreasing thickness, the shelf should deflect significantly and should rest on the lower soil. These effects will be studied in this section. 


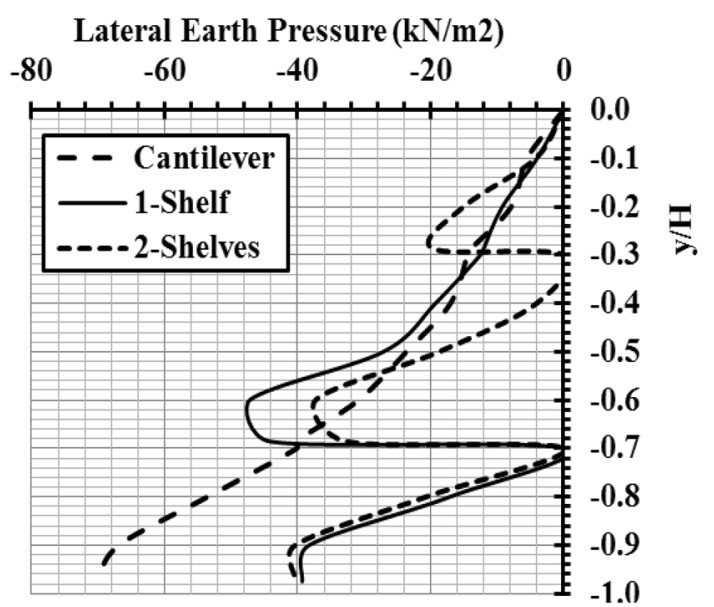

Fig. 8 Effect of providing shelves to the cantilever retaining wall

\section{Effect of shelf thickness}

The effect of shelf thickness is studied for the case of the width being constant and being equal to $2.0 \mathrm{~m}$. The case of providing a single relief shelf at a depth $h_{1} / H$ equal to 0.70 is investigated, as shown in Fig. 9. The small thickness should deflect more than the large thickness. This deflection leads the shelf to rest on the lower soil, which releases the stress directly above the shelf and increases the stress below the shelf. The deflected shelf is the weakest point of the retaining structure. With the relaxation of the shelf reinforcement and the long-term deflection of the concrete, the total deflection is increased up to breaking failure or the crack width is increased without fail. This crack breaks the continuum of the wall water insulation, which affects the serviceability and helps generate reinforcement rust. The overall stability of the retaining structure should also be

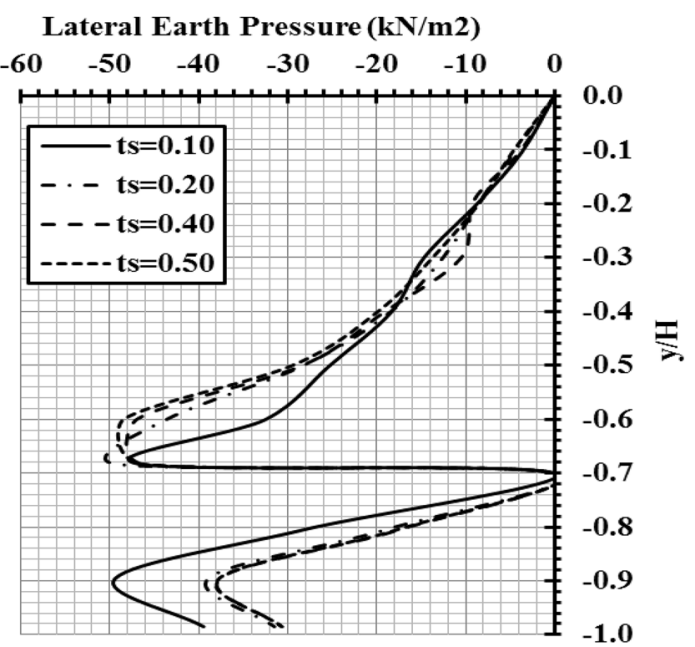

Fig. 9 Effect of shelf thickness on the lateral earth pressure distribution, single shelf at $h_{1} / H=0.70$ decreased from 1.45 to a value that is slightly more than the factor of the cantilever; i.e., approximately 1.28 . Hence, the use of the shelf provides a new failure mechanism in the retaining structure; therefore, it is not recommended to use very flexible shelves. The case of two shelves is investigated in Fig. 10. It follows the same manner of the single relief shelf but in two stages. The release of the pressure directly above the shelf increases the stress under the shelf and decreases the overall stability of the wall.

The semi-rigid and rigid shelves affect the top horizontal movement of the wall $(\Delta x)$. The decrease in the top movement is important for the subsiding of the rough settlement of the backfill. In addition, the horizontal movement is required to release the lateral earth pressure and to achieve the active pressure state. Figure 11 shows the relation between the thickness-to-width ratio $\left(\mathrm{t}_{\mathrm{s}} / \mathrm{b}\right)$ and the movement-to-height ratio $(\Delta \mathrm{x} / \mathrm{H})$. Providing a single relief shelf is an effective tool to decrease horizontal movement, especially if its level is near the top of the wall. The use of many rigid shelves is the best solution for reducing the wall deflection. Figure 12 investigates the effect of the shelf thickness on the maximum bending moment $\left(\mathrm{M}_{\max }\right)$. The maximum bending moment decreases significantly with the use of shelves. For the case of two rigid shelves, the maximum bending moment is approximately half of that from the cantilever case. For the different thicknesses, the use of a single shelf at a level near the wall bottom is better than that near the wall top.

\section{Effect of shelf width}

Here, the thickness of the shelf is constant and equal to $0.20 \mathrm{~m}$. The shelf width is varied in the study between 1.0 , 2.0 , and $3.0 \mathrm{~m}$. Single and double shelves are studied using

Lateral Earth Pressure $(\mathrm{kN} / \mathrm{m} 2)$

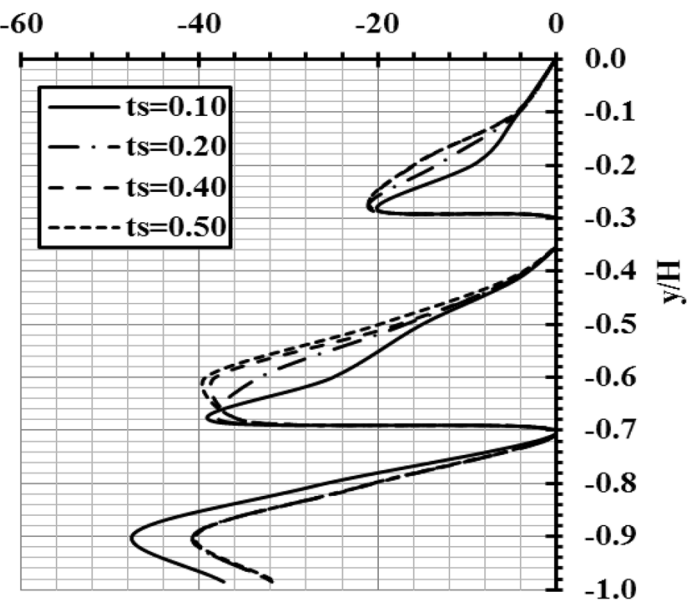

Fig. 10 Effect of shelf thickness on the lateral earth pressure distribution, two shelves 
Fig. 11 Effect of thickness to width ratio on the top movement of the wall

Fig. 12 Effect of thickness to width ratio on the acting maximum bending moment on the wall
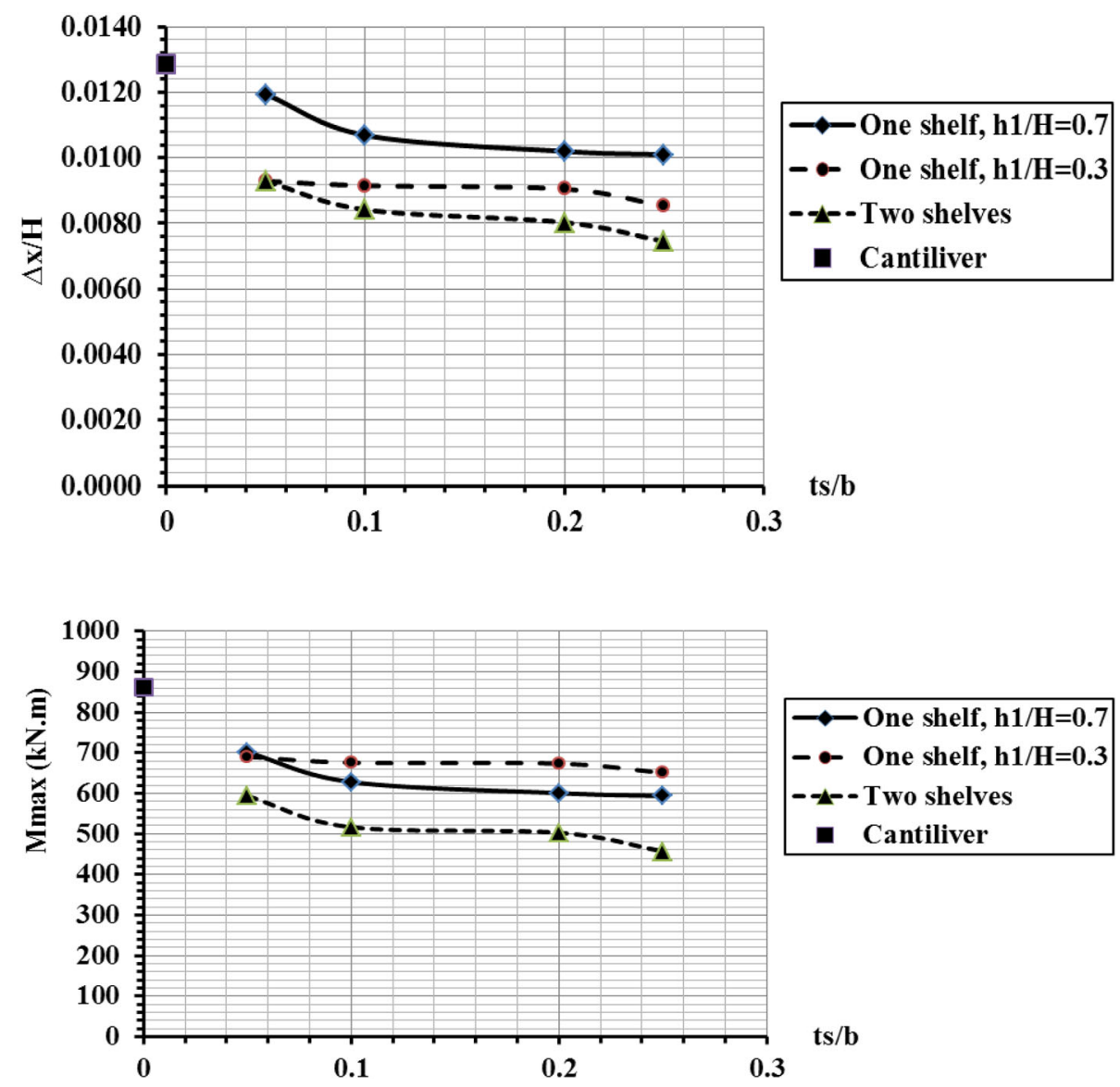

different widths. As the theoretical solutions, the rupture surface has a slope angle of $\theta$, which is equal to $(45+\varphi /$ 2). Klein [10] discussed that the shelf should theoretically be extended to the rupture surface to obtain the full effectiveness of the shelf. Therefore, the analysis of this assertion is performed using the FEM solution. Figure 13 presents the influence of the width for a single relief shelf at $\mathrm{h}_{1} / \mathrm{H}$ equal to 0.70 . It can be observed that the $1 \mathrm{~m}$ shelf, which is not extended to the rupture surface, results in a higher lateral pressure below the shelf. For the case of 2.0 and $3.0 \mathrm{~m}$ widths that are extended to the rupture surface, the distributions are similar. This conclusion is compatible with the solution of Klein [10] and demonstrates the beauty of the theoretical solutions that were previously determined in early date without using software.

Applying the analyses using two shelves is investigated in Fig. 14. In the same manner, as when using a single shelf, the $1.0 \mathrm{~m}$ shelf width results in a distribution characterized by higher values of the lateral earth pressure. On the other hand, the $2.0 \mathrm{~m}$ width for the upper shelf is not extended to the rupture surface. Therefore, the distributions of the 2.0 and $3.0 \mathrm{~m}$ widths are only slightly different. If we ignore the increase in the lateral pressure just above the shelves and obtain the best fit line, the lateral pressure

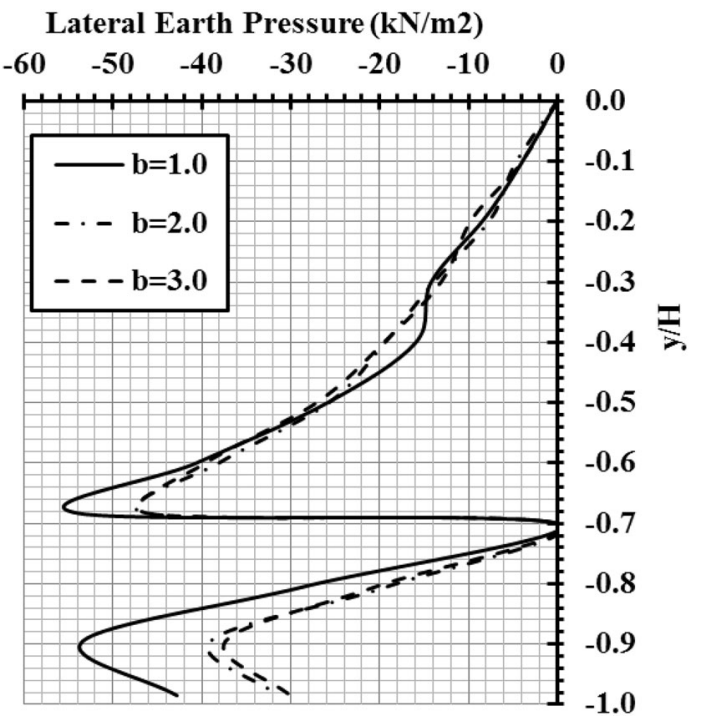

Fig. 13 Effect of shelf width on the lateral earth pressure distribution, single shelf at $h_{1} / H=0.70$

under the shelves increases in a sloped transition zone, and subsequently, it follows the lateral pressure of the cantilever case. This conclusion is also compatible with Klein's [10] solution. The other solutions presented in the 
Lateral Earth Pressure (kN/m2)

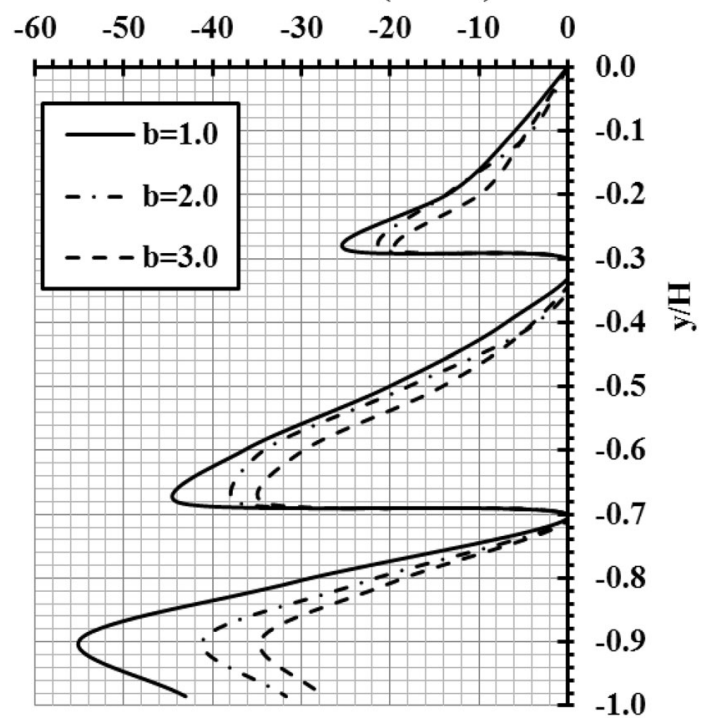

Fig. 14 Effect of shelf width on the lateral earth pressure distribution, two shelves

literature exhibit different distributions that are not compatible with the FEM solution. Measurements, as stated in the literature, were performed using very simple models or fixed-base walls to support the solution of Jumikis [9]. Previously, Yakovlev (1975) permitted the wall to move, which should occur in a realistic case, during his measurements of the lateral pressure. Now, the movement of the wall is also permitted in the solution of the FEM to find the distributions of the lateral earth pressures. The logical measurements and the solution from the FEM are compatible with these conclusions. In addition, the same distributions of the lateral pressures using the FEM were presented by Yoo et al. [18], but they neglected the FEM solutions because the distributions of the FEM were not compatible with their measurements, which were investigated using simple and fixed walls as previously discussed.

The effect of the shelf width on the wall top movement is investigated in Fig. 15. The $1.0 \mathrm{~m}$ single and double shelves result in a small decrease in the wall top movement. Increasing the width of the shelves significantly decreases the wall top movement. This decrease is the result of the decrease in the acting lateral pressure and of the increase in the shelf deflection, which rotates the wall into the backfill. The effect of the shelf width is also studied for the maximum bending moment $\left(\mathrm{M}_{\max }\right)$, as shown in Fig. 16. Providing the cantilever retaining wall with long relief shelves significantly reduces the acting maximum bending moment of the wall. It can be observed that the maximum moment is reduced from 900.0 to $300.0 \mathrm{kN}$ m by adding two long shelves $(4.0 \mathrm{~m})$. Providing this cantilever wall with a single relief shelf with a width of $2.00 \mathrm{~m}$ and a thickness of $0.20 \mathrm{~m}$, whereby the thickness- to-width ratio is 0.1 , reduces the maximum moment by approximately $30 \%$ of its original value.

\section{Effect of shelf width}

The position of the shelf logically affects the maximum bending moment and the wall top movement. This effect is studied here using the FEM solution. Different single shelf positions are studied to investigate the position that obtains the minimum top movement of the wall. Figure 17 presents the relation between the depth ratios $\left(\mathrm{h}_{1} / \mathrm{H}\right)$ and the movement ratios $(\Delta \mathrm{x} / \mathrm{H})$. It can be observed that the best position is at a depth ratio $\left(\mathrm{h}_{1} / \mathrm{H}\right)$ equal to approximately 0.30 .

The effect of the shelf position is also studied for the maximum bending moment. Figure 18 investigates the effect of the depth ratio on the acting maximum bending moment on the wall and on the shelf. The maximum moment on the shelf increases approximately linearly with increasing depth ratio. In addition, the maximum bending moment of the wall is decreased significantly with increasing depth ratio up to a depth ratio of approximately 0.30 , and subsequently, the decrease is relatively small. Therefore, the use of a depth ratio of 0.30 , results in a lower wall top movement with an appropriate bending moment of the wall and of the shelf.

\section{Calculation of maximum bending moment: finite element solution vs. Klein's [10] solution}

The method of Klein is adopted to compare its results for the maximum bending moment with that from using the FEM. This method is adopted due to the compatibility between the shapes of the lateral pressure distributions for this solution with some measurements and the FEM solution. Klein's solution for the case of a shelf depth $\left(\mathrm{h}_{1} / \mathrm{H}\right)$ equal to 0.70 and a shelf width of $2.0 \mathrm{~m}$ is presented in Fig. 19. It can be observed that the rupture surface from the wall bottom intersects the shelf. Therefore, the shelf shall be rested on the stable soil side with a width of $0.34 \mathrm{~m}$.

According to Klein's solution, the maximum bending moment at the point $(\mathrm{O})$ shall be depicted by taking the summation of the positive moments from the lateral earth pressure and the negative moment from the soil over the shelf by assuming that the shelf behaves as a cantilever. The assumption of the shelf as a cantilever is not appropriate in the case of the shelf width being extended beyond the rupture line. The better solution is to consider the shelf as fixed at the wall side and hinged at the other side. The effective free width is taken equal to the total width of the shelf. The maximum bending moment that is calculated using the updated Klein solution is equal to $697.5 \mathrm{kN} \mathrm{m} / \mathrm{m}$, whereas the FEM solution gives a maximum moment 
Fig. 15 Effect of shelf width on the top movement of the wall
Fig. 16 Effect of shelf width on the acting maximum bending moment on the wall
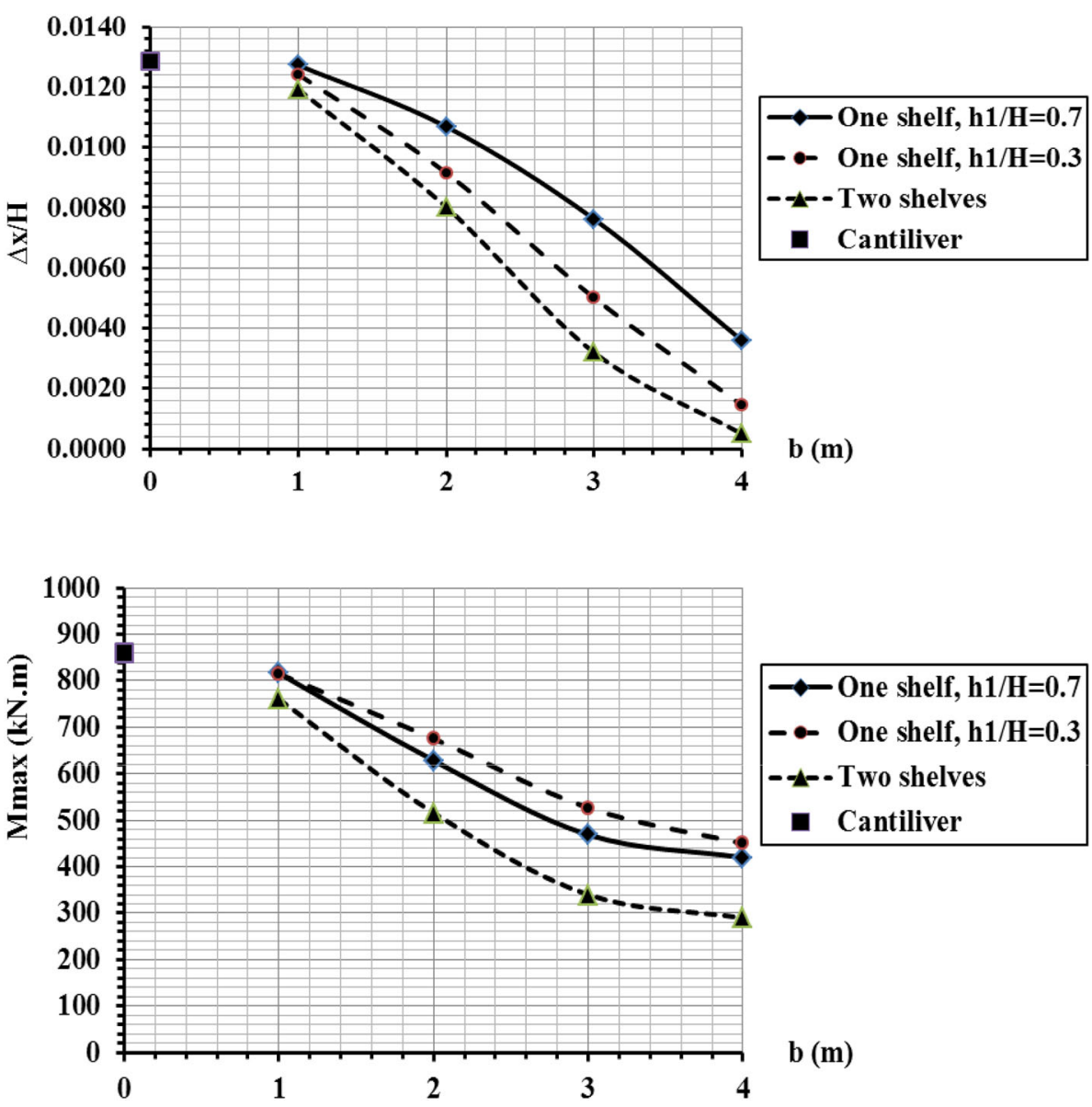

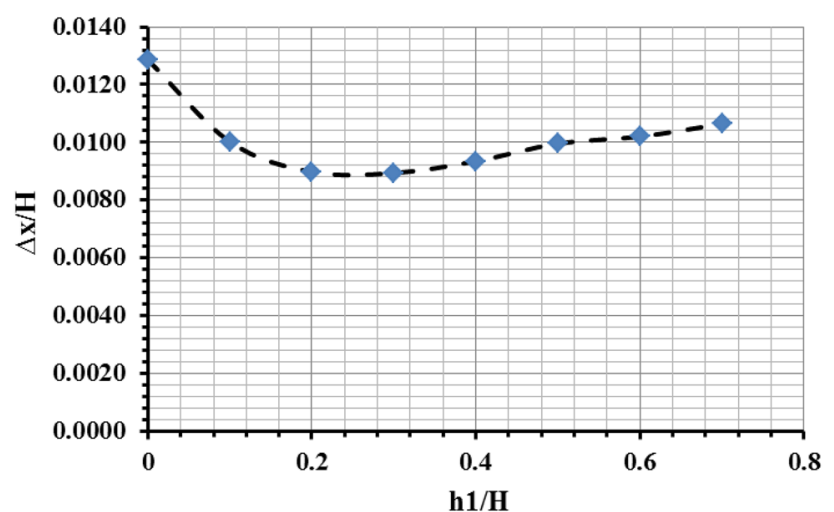

Fig. 17 Effect of shelf position on the top movement of the wall

between 700.0 and $595.0 \mathrm{kN} \mathrm{m} / \mathrm{m}$, according to the shelf thickness. These values are in good agreement with each other.

For the case of the shelf being extended to $3.0 \mathrm{~m}$, Klein's solution is presented in Fig. 20. The resulting updated maximum moment in the wall at the point $(\mathrm{O})$ is $520.0 \mathrm{kN} \mathrm{m} / \mathrm{m}$, while the $\mathrm{FE}$ solution for a thickness of $0.20 \mathrm{~m}$ gives a result of approximately $480.0-\mathrm{kN} \mathrm{m} / \mathrm{m}$.

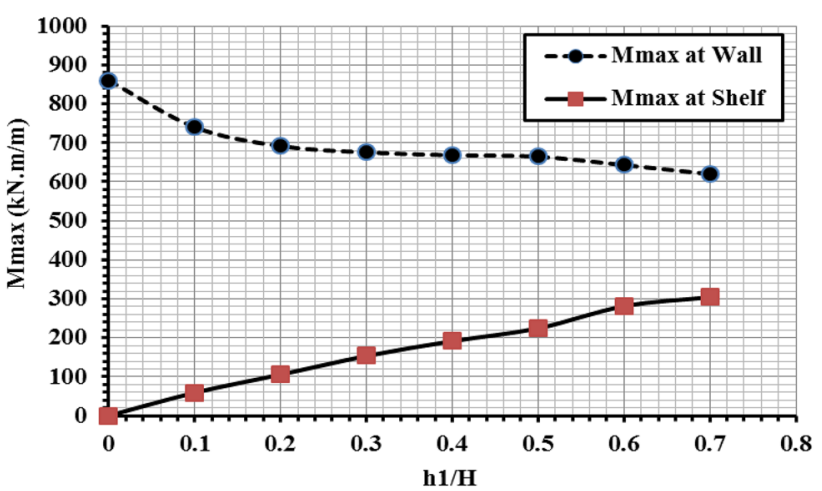

Fig. 18 Effect of shelf position on the acting maximum bending moment on the wall and shelf

When considering the shelf as a cantilever, as in Klein's solution, the resulting maximum moment is $205.0-\mathrm{kN} \mathrm{m} /$ $\mathrm{m}$, which is lower than half of the calculated value using the FEM solution.

The case of a shelf width of $2.0 \mathrm{~m}$ and a depth ratio $\left(\mathrm{h}_{1} /\right.$ $\mathrm{H})$ of 0.3 is shown in Fig. 21. In this case, the rupture surface does not intersect the shelf. Therefore, the lateral pressure returns to its original line after the defined slope of 
Fig. 19 Klein's solution for the 2.0-m shelf at depth ratio $\left(\mathrm{h}_{1} / \mathrm{H}\right)$ of 0.7

Fig. 20 Klein's solution for the 3.0-m shelf at depth ratio $\left(\mathrm{h}_{1} / \mathrm{H}\right)$ of 0.7

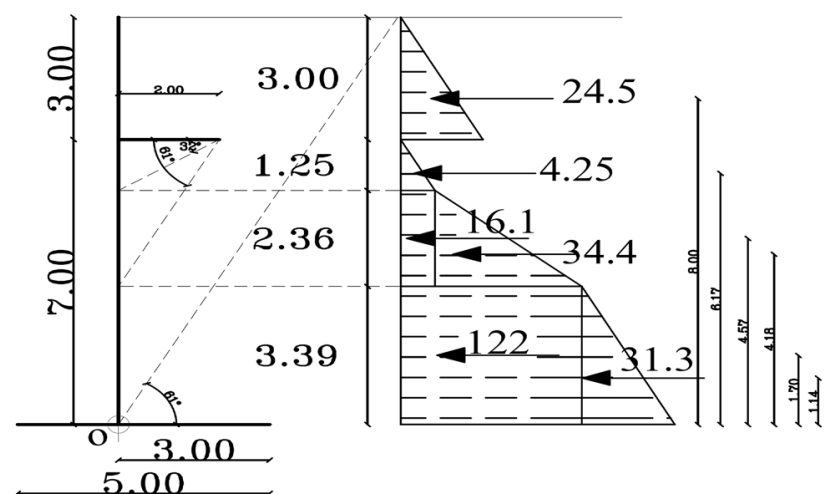

Fig. 21 Klein's solution for the 2.0-m shelf at depth ratio $\left(h_{1} / H\right)$ of 0.3

the transition zone. Klein's solution calculates the maximum bending moment by also considering the shelf as a cantilever; therefore, he deducted the moment of the shelf, which results from the above soil, from the lateral earth
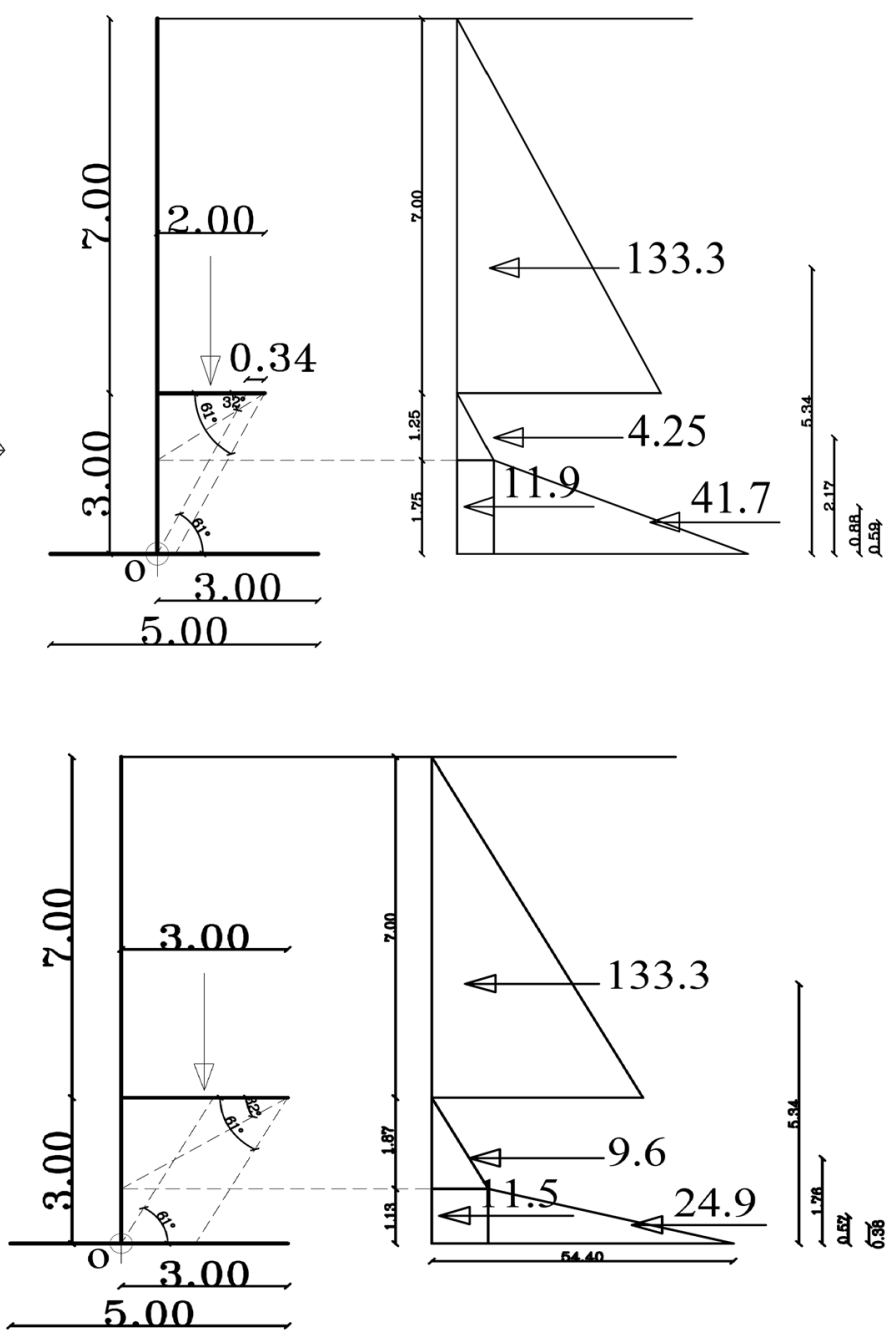

pressure moment, as stated before. Here, the shelf must behave as a cantilever in the analysis and design stages of the shelf and in the analysis of the connection between the shelf and the wall. The lateral pressure of the soil under the shelf is assumed to return to its original line from the "cantilever case"; however, the FEM solution and the measurements showed that the lateral pressure after the transition zone is slightly greater than the values of the original line. This is a result of the effect of the shelf rigidity, as discussed previously. Therefore, the maximum bending moment should be calculated while considering the positive moment from the lateral pressure and only while neglecting the negative moment from the shelf to compensate this difference. By applying the updated solution, the theoretical calculation gives a maximum bending moment of $683.0-\mathrm{kN} \mathrm{m} / \mathrm{m}$, while the FEM solution gives a maximum bending moment between 690 and 650 , according to the shelf thickness. The maximum bending moment by deducting the shelf moment using Klein's solution is $580-\mathrm{kN} \mathrm{m} / \mathrm{m}$, which is not accepted. 
Another verification of the suggested update is studied for a case of a single shelf with a width of $2.0 \mathrm{~m}$ and a depth ratio $\left(\mathrm{h}_{1} / \mathrm{H}\right)$ of 0.5 . The lateral earth pressure distribution is shown in Fig. 22. The rupture surface does not intersect the shelf.

The resulting maximum moment of the wall from the lateral earth pressure is only $665.0-\mathrm{kN} \mathrm{m} / \mathrm{m}$, and the resulting value using the FEM solution is $664.0-\mathrm{kN} \mathrm{m} / \mathrm{m}$. The results are also in good agreement with each other. By deducting the shelf moment, the value will be $490.0 \mathrm{kN} \mathrm{m} /$ $\mathrm{m}$, which is smaller than that from the FEM solution.

For the case of using two shelves, the moment of the shelves should be ignored during the calculation of the acting maximum bending moment on the wall, even if the shelves are extended or not extended after the rupture surface. The shelf moment should be considered in the stability of the rigid connection between the shelf and the wall, as in a single shelf. Several cases are analyzed theoretically using these updates and using the FEM to verify the presented update on the calculation method. As an example, the case of two shelves with a certain width of $2.0 \mathrm{~m}$ is shown in Fig. 23 for $\left(h_{1} / H=0.30\right.$ and $\left.h_{2} / H=0.30\right)$.

The maximum bending moment that is calculated from the lateral earth pressure is equal to only $532.0-\mathrm{kN} \mathrm{m} / \mathrm{m}$, and the maximum moment calculated using the FEM is equal to $520 \mathrm{kN} \mathrm{m} / \mathrm{m}$. The variances in the results from the various cases are not more than $+7 \%$ of the FEM results. This represents a good agreement between the FEM solution and the theoretical solution.

Therefore, the proposed updates or notes on Klein's solution are presented to enable the calculation of the appropriate maximum bending moment that results for the wall. The calculation of the appropriate wall movement should be performed using the FEM.

\section{Conclusions}

This paper presents a brief study of the effect of attaching shelves to a cantilever retaining wall. It was shown that few researchers have studied this special type

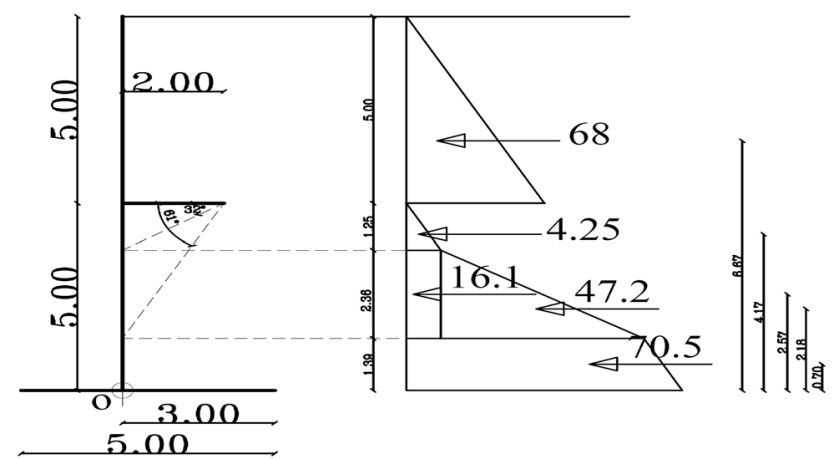

Fig. 22 Klein's solution for the 2.0-m shelf at depth ratio $\left(h_{1} / H\right)$ of 0.5

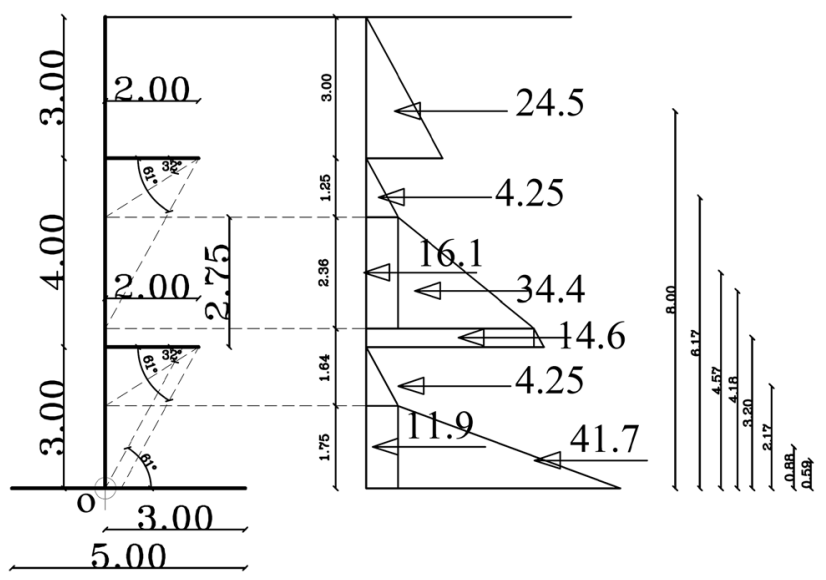

Fig. 23 Klein's solution for the retaining wall with two shelves, $\mathrm{b}=2.0-\mathrm{m}, \mathrm{h}_{1} / \mathrm{H}=\mathrm{h}_{2} / \mathrm{H}=0.30$

of retaining wall. Attaching shelves to the retaining structure leads to a decrease in the total lateral earth pressure. This decrease enables the retaining structures to become more stable and to exhibit lower bending moments. The researchers discussed presented different solutions and measurements, which have some deficiencies, as previously discussed. The effects of providing one and two shelves as well as no shelves are discussed. The shelves significantly decrease the maximum bending moment and the top movement of the wall. This decrease in the lateral pressure increases the retaining structure stability. A parametric study was conducted to investigate the effectiveness of the shelf rigidity and the shelf position on the lateral earth pressure distribution, top movement of the wall, and maximum bending moment. We demonstrated that providing the cantilever retaining wall with a single shelf at a depth ratio $\left(\mathrm{h}_{1} / \mathrm{H}\right)$ of 0.30 results in a decreased bending moment of approximately $30 \%$ of its cantilever value. The shelf width is recommended to be extended to the rupture surface with a thickness ratio $\mathrm{t}_{\mathrm{s}} / \mathrm{b}=0.10$. The solution of Klein [10] and the measurements by Yakovlev (1975) are in good agreement with the results of the FEM. Updates are provided to Klein's solution for the acting maximum bending moment of the wall to enhance the results to be more logical and to agree with the FEM solution. In the case of one shelf that is not extended to the rupture surface, the maximum bending moment should be calculated from the lateral earth pressure while only neglecting the shelf fixed-end moment and neglecting the moment from the soil above the shelf. Of course, the shelf and the rigid connection between the shelf and the wall should be analyzed using this fixed-end moment. The extension of the single shelf to the rupture surface leads the shelf to be rested on the stable soil; therefore, the fixed-end moment, from a 
fixed-hinged supported shelf, of the shelf is considered during the calculation of the acting maximum moment on the wall. For the case of more than one shelf, the shelf fixed-end moment should be neglected during the calculation of the acting maximum moment on the wall at any shelf width.

\section{Recommendations and further studies}

1. Retaining walls with shelves can be considered as effective solutions for high retaining walls when the length of the back of the wall is limited.

2. It is an effective tool for repair systems. If a wall is constructed at a level and a consultant subsequently finds the wall to be insufficient due to stability or moment considerations, a relief shelf can be provided to effectively solve the problem.

3. Comparisons between different solutions for high retaining walls should be individually performed for each case to minimize total costs.

4. It is highly recommended to study the stability of this wall during earthquakes.

5. Establishing large models to measure the real distribution as in practice is highly recommended.

6. The effect of the base and backfill soils on the resulting earth pressure distribution, wall movement, and maximum bending moment must also be studied. The effect of soil base on the wall pressure of the cantilever retaining wall was studied by Farouk and Sorour [3-6], and the Rankin method in the calculations of the active earth pressures was found to be very sufficient with changing the soil base stiffness.

Acknowledgments We would like to express our sincere appreciation and deep gratitude to the Soil-Structure Interaction Group in Egypt (SSIGE) for their advice on the design and the analyses processes.

Open Access This article is distributed under the terms of the Creative Commons Attribution 4.0 International License (http://crea tivecommons.org/licenses/by/4.0/), which permits unrestricted use, distribution, and reproduction in any medium, provided you give appropriate credit to the original author(s) and the source, provide a link to the Creative Commons license, and indicate if changes were made.

\section{References}

1. Bell FG (1987) Ground engineer's reference book. Butterworths, London

2. Discussion Paper No. 295 (1975) Design of retaining walls with relieving shelves. IRC J 35(Part 5):1153-1168

3. Farouk H, Sorour T (2014) Effect of base soil stiffness on the earth pressure of cantilever retaining walls. In: Proceeding of ISSMGE Technical Committee 207-2014 Conference, soilstructure interaction, underground structures and retaining walls, Saint Petersburg, June 16-18, 2014, Russia

4. Farouk H (2015) Effectiveness of using shelves with cantilever retaining walls. AEI 2015:627-637. doi:10.1061/9780784479070. 055

5. Farouk H (2015) Finite element analysis for the retaining wall with relief shelves. In: Brandl H, Adam D (eds) XV DanubeEuropean Conference on geotechnical engineering (DECGE 2014), 9-11 September 2014, Vienna, Austria, Paper No. 52

6. Farouk H, Farouk M (2014) Soil, foundation, and superstructure interaction for plane two-bay frames. Int J Geomech B4014003. doi:10.1061/(ASCE)GM.1943-5622.0000453

7. Fuchen L, Shile L (2008) Earth pressure calculation for retaining structure with relieving platform. Port Eng Technol 4:182

8. Jang HW (1998) Soil foundation design and example. Researchculture Publishing Company

9. Jumikis AR (1964) Mechanics of soils. D Van Nostrand Co., Inc., New Jersey

10. Klein GK (1964) Calculation of retaining walls (in Russian). Vysshaya Shkola, Moscow

11. Phatak DR, Patil V (1975) Effect of relief shelves on earth pressure. Inst Eng (India) J C1 55:156-159

12. Raychaudhuri PR (1973) Design of retaining walls with relieving shelves. Paper No. 295. IRC J 35(2):289-325

13. Yakovlev PI (1964) Experimental investigations of a new type of relieving device for retaining walls. In: Scientific papers "Hydraulic Engineering" (in Russian), No. 3, Morskoi Transport

14. Yakovlev PI (1964) Investigation of the behavior of relieving platforms of retaining walls. In: Scientific papers Hydraulic Engineering, Russian, No. 3, Morskoi Transport

15. Yakovlev PI (1965) Calculation of relieving beams. In: Scientific papers "Sea Ports," (in Russian), No. 1

16. Yakovlev PI (1966) Application of S. S. Golushkevich's method to calculation of retaining walls with relieving platforms. Izvestiya VUZOV. Stroitel's tovo Arkhitektura, No. 9

17. Yakovlev PI (1974) Experimental investigation of earth pressure on walls with two platforms in the case of breaking loads relieving on the backfill. Odessa Institute of Naval Engineers. Translated from Osnovaniya, Fundamenty Mekhanika Gruntov, No. 3, pp 7-9

18. Yoo WK, Kim BI, Moon I, Park YS (2012) Comparison of the lateral earth pressure on the retaining wall with the relieving platform by model test and numerical analysis. J Korea Acad Ind 13(5):2382-2389

19. Yoo WK, Kim BI, Yang MR, Park YS (2012) Model test study on the earth pressure of the retaining wall with the relieving platform. J Korean Soc Civ Eng 32(1C):27-35 